\title{
Palliative care for nursing home patients with dementia: service evaluation and risk factors of mortality
}

\author{
Chih-Pang Chu', Cho-Yin Huang ${ }^{1}$, Chian-Jue Kuo ${ }^{1,2,3}$, Ying-Yeh Chen ${ }^{1,4}$, Chun-Tse Chen', Tien-Wei Yang ${ }^{1,2,3}$ and \\ Hsing-Cheng Liu $^{1,2,3,5^{*}}$
}

\begin{abstract}
Background: Difficulties in prognostication are common deterrents to palliative care among dementia patients. This study aimed to evaluate the effectiveness of palliative care in reducing the extent of utilization of medical services and the potential risk factors of mortality among dementia patients receiving palliative care.

Methods: We surveyed dementia patients involved in a palliative care program at a long-term care facility in Taipei, Taiwan. We enrolled 57 patients with advanced dementia (clinical dementia rating $\geq 5$ or functional assessment staging test stage $7 \mathrm{~b}$ ). We then compared the extent of their utilization of medical services before and after the provision of palliative care. Based on multivariable logistic regression, we identified potential risk factors before and after the provision of palliative care associated with 6-month mortality.

Results: The utilization of medical services was significantly lower among dementia patients after the provision of palliative care than before, including visits to medical departments $(p<0.001)$, medications prescribed $(p<0.001)$, frequency of hospitalization $(p<0.001)$, and visits to the emergency room $(p<0.001)$. Moreover, patients dying within 6 months after the palliative care program had a slightly but not significantly higher number of admissions before receiving hospice care $(p=0.058)$ on univariate analysis. However, no significant differences were observed in multivariate analysis.

Conclusions: The provision of palliative care to dementia patients reduces the extent of utilization of medical services. However, further studies with larger patient cohorts are required to stratify the potential risk factors of mortality in this patient group.
\end{abstract}

Keywords: Palliative care, Dementia, Risk factor, Mortality

\section{Background}

Dementia is a neurodegenerative disorder that leads to a decline in multiple brain functions including memory, language, and balance and motor functions [1, 2]. Individuals with dementia generally need complex long-term care involving a multidisciplinary approach and integration of

\footnotetext{
* Correspondence: hsingcheng@gmail.com

'Department of General Psychiatry, Songde Branch (Taipei City Psychiatric Center), Taipei City Hospital, 309 Sung-Te Road, Taipei 110, Taiwan

${ }^{2}$ Department of Psychiatry, School of Medicine, College of Medicine, Taipei Medical University, Taipei, Taiwan

Full list of author information is available at the end of the article
}

medical resources [3]. The prevalence of dementia has increased in Western [1, 3, 4] and Eastern populations [5] owing to aging populations, with a marked effect on nationwide healthcare systems and a considerable socioeconomic burden [6].

Given that dementia is a progressive and irreversible disease without any treatments for cure, implementing palliative care programs for patients with dementia has been considered an appropriate strategy [7, 8]. Palliative care programs target patients at a high mortality risk due to advanced-stage diseases and are designed to

(c) The Author(s). 2020 Open Access This article is licensed under a Creative Commons Attribution 4.0 International License, which permits use, sharing, adaptation, distribution and reproduction in any medium or format, as long as you give appropriate credit to the original author(s) and the source, provide a link to the Creative Commons licence, and indicate if changes were made. The images or other third party material in this article are included in the article's Creative Commons licence, unless indicated otherwise in a credit line to the material. If material is not included in the article's Creative Commons licence and your intended use is not permitted by statutory regulation or exceeds the permitted use, you will need to obtain permission directly from the copyright holder. To view a copy of this licence, visit http://creativecommons.org/licenses/by/4.0/ The Creative Commons Public Domain Dedication waiver (http://creativecommons.org/publicdomain/zero/1.0/) applies to the data made available in this article, unless otherwise stated in a credit line to the data. 
relieve suffering and improve quality of life by reducing unnecessary or aggressive therapies [9]. Such a caregiving approach has been more extensively used among cancer patients than among dementia patients $[1,10]$. Insufficient insights into the terminal nature of dementia among caregivers and some medical professionals have limited the provision of palliative care to dementia patients [1, 11]. Furthermore, the unpredictability of the disease course $[1,2,10]$; difficulties with prognostication $[10,12]$; and lack of professional policies, guidelines [9], or funding [12] are common deterrents to the provision of palliative care among dementia patients.

Some evidence suggests an increasing trend in the utilization of palliative care among dementia patients $[10,13]$. For example, in the United States, enrollment of dementia patients to palliative care increased from < $1 \%$ to approximately 15\% from 1995 to 2014 [10]. Another US survey using national data from Medicare revealed that $>50 \%$ of nursing home patients receiving palliative services were diagnosed with dementia in 2004 and 2009 [14]; moreover, the primary expenditures for palliative care among dementia patients are the use of inpatient hospital care and treatment [15]. However, compared with patients with other clinical conditions, end-stage dementia patients often receive suboptimal palliative care $[1,12]$. The lack of highly predictable clinical variables in estimating the survival time of dementia patients has caused difficulty among caregivers and clinicians in determining the appropriate timing for deploying end-of-life management when providing care to these patients [7, 12]. Consequently, dementia patients potentially have higher chances of receiving aggressive intervention during their progressive functional decline and as they experience intermittent health conditions such as infections, dehydration, delirium, or falls $[6,10]$. Furthermore, previous studies $[16,17]$ have reported an increasing trend in the proportion of dementia patients dying in nursing homes; however, a substantial proportion of such patients still die in hospitals, thus potentially reflecting the unnecessary utilization of medical services at the end stage of life and that the concept of palliative care in dementia has not been fully adopted in the medical care community.

Limited evidence has successfully identified mortality risk factors among advanced dementia patients receiving palliative care $[12,18]$. Furthermore, evidence regarding the effectiveness of palliative care in reducing the utilization of medical services for dementia patients is inconsistent and inconclusive [6]. By analyzing data on dementia patients receiving palliative care in a nursing home in Taipei, Taiwan, we evaluated the effect of the provision of palliative care among terminal dementia patients by comparing the extent of utilization of medical services before and after a palliative care program. Furthermore, we evaluated the potential mortality risk factors among dementia patients receiving palliative care.

\section{Methods \\ Data sources}

In July 2014, a palliative care program was initiated in one nursing home in Taipei, Taiwan, by the team from the Taipei City Psychiatric Center (TCPC; Songde branch), Taipei City Hospital. Before 2014, nursing homes in Taiwan rarely provided palliative care; most of these services were provided in hospitals. TCPC has provided an intervention that integrates palliative care in nursing homes since July 2014 called the TCPC-Nursing Home Palliative Care Program. The program is operated by a multidisciplinary team from TCPC that includes board-certified neurologists, psychiatrists, psychiatric nurses, social workers, pharmacists, and clinical psychologists. In integrating the palliative care program, the team has collaborated well with the nursing staff in the nursing home. The inclusion criteria for this care program were determined in accordance with the regulations of Taiwan's National Health Insurance program. The clinical conditions of potential patients considered for enrollment in this program are carefully evaluated by the neurologists or psychiatrists in the team. The participants (nursing home inhabitants) with terminal cancer; advanced dementia (clinical dementia rating $\geq 5$ or functional assessment staging test [FAST] stage $7 \mathrm{~b}$ ); severe neurodegenerative disease other than dementia; or those with severe lung, liver, or heart disease are eligible for enrollment in this program.

The provision of care to late-stage dementia patients who are candidates for the palliative care program can be burdensome and of potentially limited clinical benefits owing to advanced cognitive and functional impairment in these patients [14]. This necessitated a transition in health care provision from futile or burdensome treatment to palliative care. Because dementia is a progressive and irreversible disorder without any cure, the implementation of the palliative care program entails several tasks, including the provision of adequate information to the families of the patients through family meetings and assisting the family members in signing a contract agreeing to palliative care and to entry into palliative care. Family meetings are held with the families of patients with terminal diseases to obtain their consent.

In this palliative care program, our program provides regular clinical services twice per week in the nursing home. These services comprise the prescription of drugs, evaluation of food intake, and the use of NG or Foley tubes. The multidisciplinary team is available $24 \mathrm{~h}$ per day to provide emergency consultations by an instant messaging software and an interim service would be arranged if the problem could not be resolved on line. The value of palliative care includes a reduction in the utilization of 
medical services (such as invasive treatment and unnecessary visits to the emergency room) and inconvenience to patients and their families. If a patient receiving palliative care dies, team members (particularly clinical psychologists) provide the post-mortem care to counsel the grieving family members, and the medical professionals (neurologists or psychiatrists) assist the family members in completing formalities related to the death certificate to facilitate the process of the funeral.

By October 2017, 79 patients were enrolled in this program (Fig. 1), 65 agreed to undergo the palliative care program, and 57 had dementia and were included in this study for further assessment. The endpoint of the study was December 31, 2017. The Institutional Review Board of Taipei City Hospital approved the protocol for this study (TCHIRB-10707101-E). The survey used in the present study was developed for this study and has not previously been published elsewhere.

\section{Variables}

We recorded the age, sex, physical comorbidities, and cognitive function of the patients upon admission to the nursing home and after entering palliative care.
Furthermore, information regarding the utilization of health services, including the number of medical departments visited, number of prescribed medications, frequency of hospitalization, length of intensive care unit (ICU) admission, and the number of visits to the emergency department, were recorded before and after initiation of hospice care. We used the Barthel index [19] to evaluate functional abilities and the Mini-Mental Status Examination [20] to measure cognitive abilities. Mortality status on day 180 after the commencement of palliative care was examined. This study adopted the criteria for hospice eligibility in the Medicare system, requiring an estimated survival of less than 6 months $[18,21]$. We described the survey in Additional file 1 and listed the study framework in the supplement e-Figure 1 (Please see Additional file 2).

\section{Statistical analysis}

Descriptive analyses were performed to examine the demographic and clinical characteristics of dementia patients receiving palliative care. Moreover, we compared the average monthly indices for health care utilization

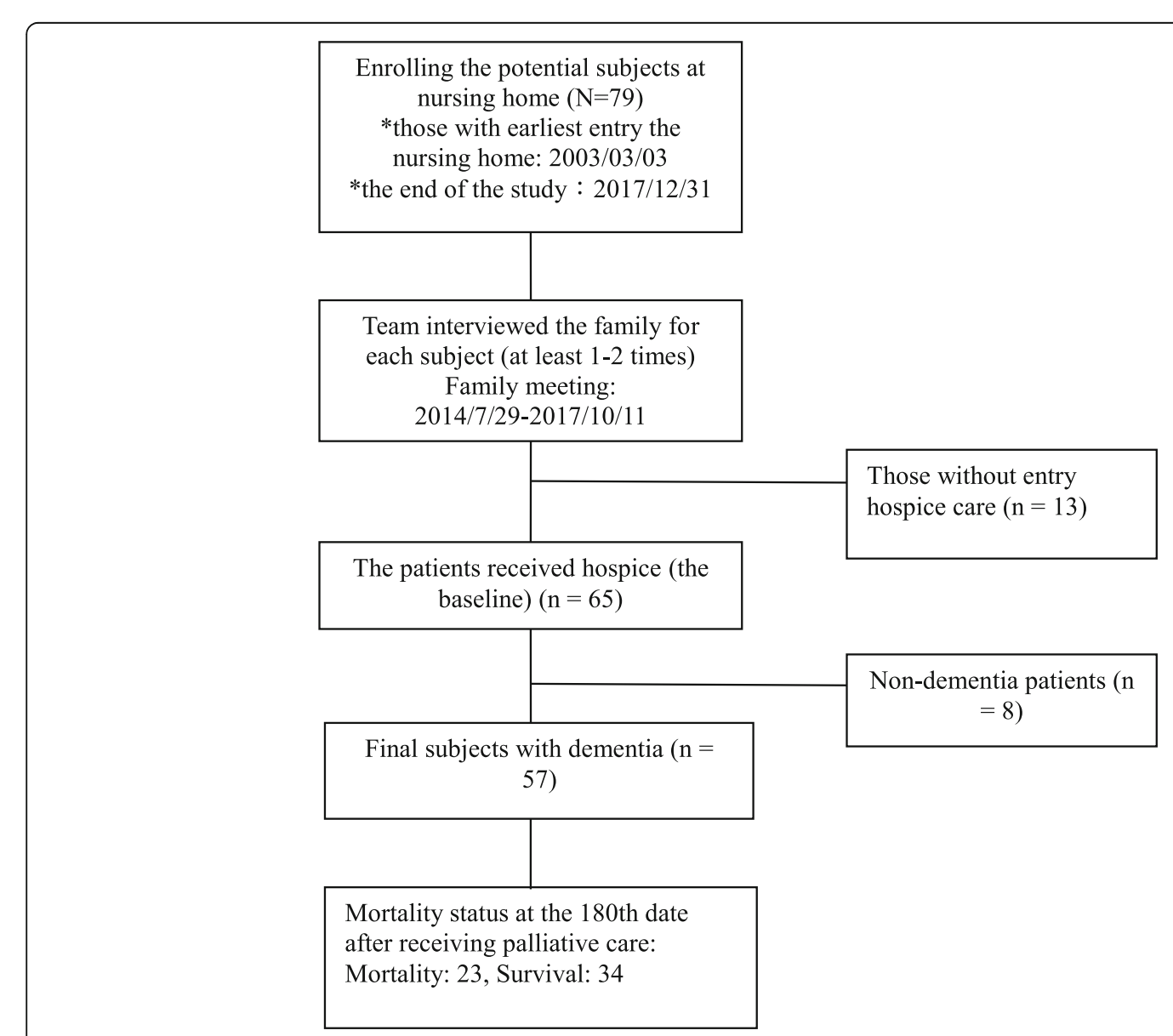

Fig. 1 Flowchart of the study 
before and after the provision of palliative care via a paired $t$ test.

Compared with cancer patients receiving palliative care, dementia patients are more likely to remain in palliative care more than 6 months and require face-to-face recertification, per the regulations of the Centers for Medicare and Medicaid Services [22]. Accordingly, middle-term mortality was defined as patients dying within $180 \mathrm{~d}$ of receiving palliative care, and middleterm mortality was considered the endpoint to evaluate the potential risk factors regarding the extent of palliative care with such an endpoint. The potential risk factors that were taken as the clinical variables before palliative care, those upon receiving palliative care, and those after the provision of palliative care are summarized in Table 3. Univariate logistic regression analysis was performed to identify such variables associated with middle-term mortality within $180 \mathrm{~d}$ of receiving palliative care. Furthermore, the potential variables were subjected to multivariate logistic regression analysis with a backwards stepwise selection strategy, and those with $p<0.05$ were retained in the final model.

Statistical significance was set at a two-tailed $p$-value $<0.05$. All analyses were performed using SAS software, version 9.4 (SAS Institute Inc., Cary, NC, USA).

\section{Results}

\section{Patient characteristics}

The demographic and clinical characteristics of dementia patients receiving hospice care are listed in Table 1 . In most cases, the patients' children signed the contract for palliative care. Most of family members participated in family meetings once and then signed the contract for palliative care.
Information regarding the demographic data of the participants upon first receiving institutionalized hospice care are listed in supplement e-Table 1 (Please see Additional file 3). The clinical characteristics of patients upon admission to the nursing home and upon first entering institutionalized hospice care are listed in supplement e-Table 2 (Please see Additional file 4). Regarding the co-morbid conditions at the entry of nursing home, hypertension is the most prevalent one $(57.8 \%)$, then stroke (38.6\%), diabetes mellitus (26.3\%), nonhypertension cardiovascular disease (22.8\%).

\section{Service evaluation}

Differences in the utilization of medical services among the dementia patients per month before and after the provision of palliative care are summarized in Table 2 . The utilization of medical services, including visits to hospital departments $(p<0.001)$, medications prescribed $(p<0.001)$, frequency of hospitalization $(p<0.001)$, and visits to the emergency room $(p<0.001)$, was significantly lower after entry into palliative care.

\section{Factors associated with middle-term mortality}

The potential factors associated with middle-term mortality $180 \mathrm{~d}$ after receiving palliative care are listed in Table 3. Univariate analyses revealed that patients dying within 180 $\mathrm{d}$ had more than two admissions before receiving hospice care with borderline statistical significance $(p=0.058)$ than did those who survived after $180 \mathrm{~d}$. Otherwise, no significant risk factor was observed between patients surviving $180 \mathrm{~d}$ after palliative care and those who died within $180 \mathrm{~d}$ in terms of age upon entering hospice care, hospital departments visited per month before commencing palliative care, and medications prescribed per month before hospice care.

Table 1 Characteristics of dementia patients receiving palliative care

\begin{tabular}{|c|c|c|}
\hline Characteristics & Men $(N=22)$ & Women $(N=35)$ \\
\hline & Mean (SD) & Mean (SD) \\
\hline Age at the receiving palliative care $(y / 0)$ & $88.2(5.6)$ & $89.2(5.2)$ \\
\hline Duration from entry the nursing home to the receiving palliative care (years) & $4.7(4.1)$ & $5.2(4.2)$ \\
\hline Duration from first family meeting to the entry of palliative care (days) & $24.1(78.1)$ & $19.2(45.8)$ \\
\hline The person signed contract of palliative care & $N(\%)$ & $N(\%)$ \\
\hline Couple & $4(18.2)$ & $1(2.9)$ \\
\hline Child & $14(63.6)$ & $30(85.7)$ \\
\hline Others & $4(18.2)$ & $4(11.4)$ \\
\hline \multicolumn{3}{|l|}{ Family members participated Family meeting } \\
\hline $1-2$ & $15(68.2)$ & $26(71.1)$ \\
\hline$>2$ & $7(31.8)$ & $9(28.9)$ \\
\hline \multicolumn{3}{|l|}{ Times of Family Meeting } \\
\hline 1 & $25(92.6)$ & $30(78.9)$ \\
\hline 2 (twice) & $2(7.4)$ & $7(18.4)$ \\
\hline
\end{tabular}


Table 2 Differences in the utilization of medical services before and after the provision of palliative care

\begin{tabular}{llll}
\hline Characteristics (Average number per month) & Pre-palliative-care stage ${ }^{\mathrm{b}}(N=57)$ & Post-palliative-care stage $(N=57)^{c}$ Statistics $^{\mathrm{a}}$ \\
\hline The departments visited & Mean $(S D)$ & Mean (SD) & $0.07(0.26)$ \\
Number of medications & $2.23(0.96)$ & $5.39(2.51)$ & $P<0.001$ \\
Number of hospitalizations & $7.84(3.04)$ & $0.07(0.32)$ & $P<0.001$ \\
Length of stay (days) & $1.42(1.45)$ & $0.56(3.21)$ & $P<0.001$ \\
Length of stay of ICU admissions (days) & $19.72(22.74)$ & $0.00(0.00)$ & $P<0.001$ \\
Number of visits on emergency department & $1.49(5.82)$ & $0.02(0.13)$ & $P=0.058$ \\
\hline
\end{tabular}

aased on paired $t$ test

${ }^{\mathrm{b}}$ The average period of contribution in months (SD) in the prepalliative care stage: 10.53 (3.25)

'The average period of contribution in months (SD) in the postpalliative care stage: 9.07 (8.73)

Furthermore, no significant factor was retained in multivariate analysis.

\section{Discussion}

\section{Major findings}

This study made two major findings. First, the utilization of medical services significantly decreased after the provision of palliative care to dementia patients compared with that before. Second, no significant mortality risk factors were identified among advanced dementia patients receiving palliative care.

\section{Characteristics of patients and service providers}

All patients herein had a primary diagnosis of dementia, with hypertension and stroke being the most common comorbidities. Most of them did not have cancer. Moreover, most of these patients were bedridden, received tube feeding, and displayed deteriorated cognitive function upon entering the palliative care program compared with when they first entered the facility.

Regarding previous models used for delivering palliative care in nursing homes $(\mathrm{NH})$, a study from the United States [24] reported three successful models for providing palliative care to nursing home residents, summarized as follows. Model 1: Palliative Care Consult Service-The palliative care service model involves external consultants on request of the $\mathrm{NH}$ medical director, the patient's attending physician, or the $\mathrm{NH}$ director of nursing. Model 2: Nursing Home-Based Palliative Care-Nursing homes employ their own palliative care personnel. Model 3: Nursing Home-Palliative Care Partnerships-Well-integrated palliative care is provided in a nursing home [25]. The TCPC-nursing home palliative care model discussed herein is a hybrid of Model 1 and Model 3, wherein our medical professionals provide consultations, and regular care is provided at the nursing home. Our multidisciplinary model has enhanced access to palliative care for all nursing home residents. The team offers biweekly patient visits and monthly family meetings with their caregivers. Furthermore, medical team meetings involving all team members are held on a monthly basis to evaluate current treatment regimens.

\section{Service evaluation}

Evidence regarding the effectiveness of palliative care in reducing the utilization of medical services among dementia patients is mixed. In accord with our finding regarding a reduction in the utilization of medical services after the provision of palliative care to terminal dementia patients, a study [26] reported that advanced dementia patients receiving palliative care at nursing homes in the United States received fewer medications, injections, feeding tubes, intravenous fluids, and medical services and they had a lower likelihood of hospital death than those who did not receive palliative care. Furthermore, a nationwide 5 -year cohort study in Taiwan by Chen et al. [6] reported that palliative care is associated with a reduction in futile or burdensome treatments among dementia patients, except for tube feeding. However, subgroup analysis of dementia patients without a cancer diagnosis revealed that palliative intervention was associated only with low risks for cardiopulmonary resuscitation. By contrast, a randomized control trial in the United States involving hospitalized patients with advanced dementia receiving palliative intervention reported no effect on tube feeding, mechanical ventilation, and do-not-resuscitate decisions [27].

Some potential explanations regarding the discrepancies among these studies are the following. First, different comorbidities among the study patients may affect the correlation between the provision of palliative care and the utilization of medical services. Studies from Taiwan have reported different patterns in the use of lifesaving procedures depending on patient diagnoses (i.e., dementia, cancer, or both) [28]. For instance, patients with dementia had a higher frequency of admission to the hospital and the ICU and a longer duration of hospitalization than those with cancer $[6,29]$, indicating that a reduction in burdensome treatments among advanced dementia patients under palliative care among 
Table 3 Before and after palliative care factors associated with mortality within $180 \mathrm{~d}$ of the provision of palliative care

\begin{tabular}{lll}
\hline Characteristics & $\begin{array}{l}\text { Mortality within } 6 \text { months after palliative } \\
\text { care }(N=23)\end{array}$ & $\begin{array}{l}\text { Survival at } \\
\text { care }(N=\end{array}$ \\
\hline $\begin{array}{l}\text { Before palliative care } \\
\text { (baseline) }\end{array}$ & $\boldsymbol{N}(\%)$ & $\mathbf{N}(\%)$ \\
Age at receiving palliative care $(y / 0)$ & \\
$\leq 85$ & $5(18.5)$ & $6(17.6)$ \\
$86-90$ & $8(29.6)$ & $15(44.1)$ \\
$>90$ & $10(51.9)$ & $13(38.2)$
\end{tabular}

Number of departments visited per month before palliative care

$\begin{array}{lll}1 & 2(8.7) & 9(26.5) \\ 2 & 13(56.5) & 17(50.0) \\ >2 & 8(34.8) & 8(23.5)\end{array}$

(26.5)

$8(23.5)$

Number of medications used per month before palliative care

$\begin{array}{lll}0-5 & 2(8.7) & 10(29.4) \\ >5 & 21(91.3) & 24(70.6)\end{array}$

Number of admissions within 1 year before palliative care

0

$$
\begin{aligned}
& 5(21.7) \\
& 6(26.1) \\
& 12(52.2)
\end{aligned}
$$$$
1
$$

ICU admission within 1 year before palliative care
Yes
$4(17.4)$
$1(2.9)$
No
$19(82.6)$
$33(97.1)$

Number for ER visits within 1 year before palliative care
0
$18(78.3)$
25 (73.5)
$1-6$
$5(21.7)$
$9(26.5)$

\section{At receiving palliative care}

Cognitive impairment

$\begin{array}{lll}\text { Severe } & 23(100) & 31(91.2) \\ \text { Moderate } & 0(0) & 2(5.9) \\ \text { Mild } & 0(0) & 1(2.9) \\ \text { Mobility } & & \\ \text { Bedridden } & 22(95.7) & 26(76.5) \\ \text { Wheelchair } & 1(4.3) & 8(23.5) \\ \text { Intake } & & 28(82.4) \\ \text { NG tube feeding } & 20(87.0) & 6(17.6) \\ \text { Oral feeding } & 2(8.6) & 0(0) \\ \text { Gastroenteric tube } & 1(4.3) & \\ \text { feeding } & & 20(58.8) \\ \text { Urination } & & 11(32.4) \\ \text { Diaper } & 13(56.5) & 3(8.8) \\ \text { urinary tube } & 9(39.1) & \\ \text { Bladder fistula/ } & 1(4.3) & 16(47.1) \\ \text { Intestinal fistula } & & 1(2.9) \\ \text { Respiratory function } & & \\ \text { Spontaneous respiration } & 6(26.1) & \\ \text { Tracheostomy } & 2(8.7) & \end{array}$

Odds ratio ${ }^{\mathrm{a}} \quad 95 \% \mathrm{Cl}^{\mathrm{a}} \quad P$ value $^{\mathrm{a}}$

$\begin{array}{lll}\text { Reference } & - & - \\ 0.64 & 0.15-2.77 & 0.550 \\ 0.92 & 0.22-3.92 & 0.914\end{array}$

Reference

$3.44 \quad 0.63-18.72 \quad 0.153$

$\begin{array}{lll}4.50 & 0.73-27.74 & 0.105\end{array}$

Reference -

$\begin{array}{lll}4.38 & 0.86-22.27 & 0.075\end{array}$

$\begin{array}{lll}\text { Reference } & - & - \\ 0.54 & 0.13-2.24 & 0.396 \\ 4.32 & 0.95-19.58 & 0.058\end{array}$

Reference -

$0.14 \quad 0.02-1.38 \quad 0.093$

Reference -

$\begin{array}{lll}0.77 & 0.22-2.69 & 0.684\end{array}$

$\begin{array}{lll}\text { Reference } & - & - \\ 0 & 0 & 1.000 \\ 0 & 0 & 0.999\end{array}$

Reference -

$\begin{array}{lll}0.15 & 0.02-1.28 & 0.082\end{array}$

Reference - _ -

$\begin{array}{lll}0.47 & 0.09-2.56 & 0.380\end{array}$

$\begin{array}{lll}2.26 & 0 & 1.000\end{array}$

Reference - -

$\begin{array}{lll}1.26 & 0.41-3.87 & 0.688\end{array}$

$051 \quad 0.48-5.48 \quad 0.581$

Reference - -

$\begin{array}{lll}5.33 & 0.41-70.20 & 0.203\end{array}$ 
Table 3 Before and after palliative care factors associated with mortality within $180 \mathrm{~d}$ of the provision of palliative care (Continued)

\begin{tabular}{|c|c|c|c|c|c|}
\hline Characteristics & $\begin{array}{l}\text { Mortality within } 6 \text { months after palliative } \\
\text { care }(N=23)\end{array}$ & $\begin{array}{l}\text { Survival at least } 6 \text { months after palliative } \\
\text { care }(N=34)\end{array}$ & & & \\
\hline Need oxygen & $15(39.1)$ & $17(47.1)$ & 2.35 & $0.73-7.56$ & 0.151 \\
\hline Barthel Index, mean/SD & $0(0)$ & $0(0)$ & - & - & - \\
\hline MMSE, mean [23] & $9.95(0.31)$ & $9.87(0.52)$ & 0.82 & $0.20-3.35$ & 0.778 \\
\hline \multicolumn{6}{|l|}{ After palliative care } \\
\hline \multicolumn{6}{|c|}{ Number of departments visited per month after palliative care } \\
\hline 0 & $21(91.3)$ & $32(94.1)$ & Reference & - & - \\
\hline$\geq 1$ & $2(8.7)$ & $2(5.9)$ & 1.52 & $0.20-11.67$ & 0.685 \\
\hline \multicolumn{6}{|c|}{ Number of medications use per month after palliative care } \\
\hline $0-5$ & $10(43.5)$ & $22(64.7)$ & Reference & - & - \\
\hline$>5$ & $13(56.5)$ & $12(35.3)$ & 2.38 & $0.81-7.04$ & 0.116 \\
\hline \multicolumn{6}{|c|}{ Number of admissions after palliative care } \\
\hline 0 & $21(91.3)$ & $33(97.1)$ & Reference & - & - \\
\hline$\geq 1$ & $2(8.7)$ & $1(2.9)$ & 3.14 & $0.27-36.86$ & 0.362 \\
\hline \multicolumn{6}{|c|}{ ICU admission after palliative care } \\
\hline Nil & $23(100)$ & $34(100)$ & & & \\
\hline \multicolumn{6}{|c|}{ Number of ER visits after palliative care } \\
\hline 0 & $23(100)$ & $33(97.1)$ & Reference & - & - \\
\hline 1 & $0(0)$ & $1(2.9)$ & 0.00 & 0 & 1.000 \\
\hline
\end{tabular}

Taiwanese inpatients is more consistent among those with cancer. Furthermore, the proportion of cancer diagnoses was higher among the study patients than among dementia patients who did not receive palliative care [6]. In brief, having cancer could potentially be considered a protective factor against the use of burdensome treatment.

Second, the lack of guidelines regarding palliative care could result in differences in service patterns in palliative interventions among dementia patients in different studies, resulting in differences in the quality of care. Studies investigating staff perspectives on palliative care in dementia have reported that having limited guidelines that result in chaotic care is not uncommon from the perspective of clinical practitioners [1,9]. Moreover, cultural differences regarding death and end-of-life issues could play a role in the service pattern of palliative care. For example, Taiwanese culture is based on principles of Confucianism, Taoism, and Buddhism, which have influenced Taiwanese individuals for thousands of years, particularly with respect to death [30]. Such cultural factors, including aspects of Confucian, Taoist, and Buddhist philosophies, influence the sense of autonomy of older residents, and they tend to rely on others to make decisions for them. Thus, when considering enrollment in the palliative care program, the team had to respect the family-oriented decision-making process of the older residents because it reflects a personal choice to make joint decisions with the family. The professionals would mediate communication between older residents and their families regarding concerns related to end-of-life care [30].

Furthermore, studies in Taiwan have reported that advanced dementia patients tend to more burdensome treatments during their last year of life in Eastern countries than in Western countries [29]. Moreover, discrepancies in the preferences of patients and caregivers regarding end-of-life management decisions are common [23, 31]. By contrast, studies in North America [32, 33 ] and Europe [34, 35] have reported a lower proportion (approximately 2-25\%) of tube feeding among advanced dementia patients at the end stage of life compared with the proportion reported in studies conducted in Asia, where $>50 \%$ of dementia patients have been reported to be given enteral feeding $[6,35]$.

Our study investigated a rather homogenous group of patients without cancer and determined that by providing an explanation and psychoeducation on the terminal nature and disease course of dementia and the core value of palliative care, the quality of life of patients and their caregivers may be enhanced; moreover, the implementation of palliative care could significantly reduce burdensome treatments among dementia patients.

\section{Potential risk factors for the middle-term mortality}

In this study, we could not identify significant mortality risk factors among advanced dementia patients receiving palliative care, which is consistent with previous studies. 
Lack of prognostic measures regarding the estimation of the survival duration among dementia patients deterred making decisions regarding the ideal timing for palliative care referral and the allocation of medical resources $[1$, $6,10]$. Importantly, under such circumstances, it is difficult for patients, families, and even clinicians to view dementia as a terminal condition. Studies on the survival of dementia patients have reported inconsistent findings with respect to survival duration, finding a mean or median survival duration in a range of approximately 3-10 years [7]. Studies have previously identified potential prognostic factors and mortality risk factors among dementia patients. For instance, a study in the United States [36] reported cancer, diabetes, the onset of organ failure, and mechanical ventilation as prognostic factors of hospice referral among dementia patients. Moreover, the U.S. National Hospice and Palliative Care Organization developed prognostic criteria for survival in dementia and as a tool to determine Medicare benefits for hospice care; according to their criteria, patients at advanced stages of the disorder (FAST stage 7c) with one or more nutritional (i.e., > 10\% weight loss) or medical complications (i.e., recurrent sepsis, pressure sore) are more susceptible to death within 6 months [10]. However, the prognostic accuracy of these criteria have been questioned previously [18, 21]. Mitchell et al. further developed the Mortality Risk Index [21] as well as the Advanced Dementia Prognostic Tool [18], which used the dataset of nursing home residents in the United States to establish 12 items-age, sex, nursing home stay, shortness of breath, pressure ulcers, activities of daily living scale, bedfast most of day, insufficient oral intake, bowel incontinence, body mass index, recent weight loss, congestive heart failure-with modest predictability of death within 6 months among nursing home patients with dementia. However, the criteria validity among non-nursing home patients has not yet been examined. Thus far, there is a lack of consensus among studies worldwide regarding appropriate prognostic measures for dementia [1, 7], and our study further affirmed this observation. Univariate analysis herein revealed that more admissions before entering a hospice is a possible risk factor of 6-month mortality, potentially indicating that these patients already had multiple health conditions and were more susceptible to death. It is reasonable to conclude that patients with advanced disease stages and poor medical conditions have poor disease outcomes.

\section{Limitations}

This study has several limitations. First, our patient cohort was relatively small and had moderate statistical power. This study preliminarily investigated the potential risk factors associated with the middle-term mortality endpoint in an exploratory manner. Hence, future studies with larger patient cohorts are required to investigate the predictors associated with such an endpoint.
Second, the study site was a nursing home located in a major city in Taiwan; hence, these results are not representative of the nationwide population. Nevertheless, unlike in previous studies, this study included a homogenous patient cohort with a primary diagnosis of dementia without complicated comorbidities under a standard treatment regimen.

\section{Conclusions}

The present results have several clinical implications for professionals providing palliative care to advanced dementia patients. This evidence-based study found a significant reduction in the utilization of medical services, including visits to hospital departments, medications prescribed, number of hospitalizations, and visits to the emergency room, after the provision of palliative care to dementia patients. However, this study did not reveal any significant mortality risk factors among advanced dementia patients receiving palliative care, which precludes decisions regarding the ideal timing for palliative care referral and the allocation of medical resources. This study emphasizes the need for an integrated palliative care intervention for terminal dementia patients in nursing homes. Future studies with larger patient cohorts are required to stratify the potential prognostic factors of mortality in this patient group.

\section{Supplementary information}

Supplementary information accompanies this paper at https://doi.org/10. 1186/s12904-020-00627-9.

Additional file 1. The survey of the present study.

Additional file 2: e-Figure 1. Study framework.

Additional file 3: e-Table 1. Demographic data of the participants upon first receiving institutionalized palliative care.

Additional file 4: e-Table 2. Clinical characteristics of the patients upon entry into the nursing home and upon receiving institutionalized palliative care.

Abbreviations

FAST: Functional Assessment Staging Test; CDR: Clinical Dementia Rating Scale; NHI: National Health Insurance; MMSE: Mini-Mental Status Examination; ADEPT: Advanced Dementia Prognostic Tool; DNR: Do-not-resuscitate; ICU: Intensive care unit

\section{Acknowledgments}

The authors thank Wei-Hsin Li, BS, with the Department of General Psychiatry, Taipei City Psychiatric Center, Taipei City Hospital, for data management and help with the statistical analyses. This manuscript was edited by Wallace Academic Editing

\section{Authors' contributions}

$\mathrm{CPC}, \mathrm{HCL}, \mathrm{HCL}$ designed the study. $\mathrm{CPC}$ and $\mathrm{HCL}$ conducted the study. $\mathrm{CYH}$ and YYC conducted the literature review. CJK and YYC conducted the data analysis. CPC, CYH and HCL drafted the manuscript. CTC and TWY participated in the interpretation of the data and made critical revisions to the manuscript for important intellectual content. All authors read and approved the final manuscript. 


\section{Funding}

This research was supported by grants from the Ministry of Science and Technology, Taiwan (MOST 108-2314-B-532-005) and Taipei City Hospital (10501-62-015). The funding sources had no involvement in the study design, data collection, analysis, interpretation of data, writing of the report, or decision to submit the paper for publication.

\section{Availability of data and materials}

The data collection transcripts are available on reasonable demand to the corresponding author.

\section{Ethics approval and consent to participate}

The Institutional Review Board of Taipei City Hospital approved the protocol for this study (TCHIRB-10707101-E). Due to participants' incapable of understanding the content of this study, the written consents were obtained by their family guardians for participation of this study.

\section{Consent for publication}

Not applicable.

\section{Competing interests}

The authors declare having no competing interests.

\begin{abstract}
Author details
'Department of General Psychiatry, Songde Branch (Taipei City Psychiatric Center), Taipei City Hospital, 309 Sung-Te Road, Taipei 110, Taiwan.

${ }^{2}$ Department of Psychiatry, School of Medicine, College of Medicine, Taipei Medical University, Taipei, Taiwan. ${ }^{3}$ Psychiatric Research Center, Taipei Medical University Hospital, Taipei, Taiwan. ${ }^{4}$ Department of Public Health, National Yang-Ming University, Taipei, Taiwan. ${ }^{5}$ University of Taipei, Taipei, Taiwan.
\end{abstract}

\section{Received: 27 May 2019 Accepted: 5 August 2020}

Published online: 12 August 2020

\section{References}

1. Hill E, Savundranayagam MY, Zecevic A, Kloseck M. Staff perspectives of barriers to access and delivery of palliative Care for Persons with Dementia in long-term care. Am J Alzheimers Dis Other Dement. 2018. https://doi.org/ 10.1177/1533317518765124.

2. Sampson EL, Thuné-Boyle I, Kukkastenvehmas R, Jones L, Tookman A, King M, MR B. Palliative care in advanced dementia; A mixed methods approach for the development of a complex intervention. BMC Palliat Care. 2008;7:8.

3. Houttekier D, Cohen J, Bilsen J, Addington-Hall J, Onwuteaka-Philipsen BD. L D: place of death of older persons with dementia. A study in five European countries. J Am Geriatr Soc. 2010;58(4):751-6.

4. Aoun SM, Toye C, Slatyer S, Robinson A, Beattie E. A person-centred approach to family carer needs assessment and support in dementia community care in Western Australia. Health Soc Care Community. 2018;26: e578-86.

5. Yang YH, Meguro K, Kim SY, Shim YS, Yu X, Chen CL, Wang H, Lam L, Senanarong V, Dominguez J, et al. Impact of Alzheimer's disease in nine Asian countries. Gerontology. 2016;62(4):425-33.

6. Chen PJ, Liang FW, Ho CH, Cheng SY, Chen YC, Chen YH. Association between palliative care and life-sustaining treatments for patients with dementia: a nationwide 5-year cohort study. Palliat Med. 2018;32(3):622-30.

7. van der Steen JT, Radbruch L, Hertogh CM, de Boer ME, Hughes JC, Larkin P, Francke AL, Jünger S, Gove D, Firth P, et al. White paper defining optimal palliative care in older people with dementia: a Delphi study and recommendations from the European Association for Palliative Care. Palliat Med. 2014;28(3):197-209

8. Murphy E, Froggatt K, Connolly S, O'Shea E, Sampson EL, Casey D. D D: palliative care interventions in advanced dementia. Cochrane Database Syst Rev. 2016;12:CD011513.

9. Davies N, Maio L, Vedavanam K, Manthorpe J, Vernooij-Dassen M. S; I, team. IR: barriers to the provision of high-quality palliative care for people with dementia in England: a qualitative study of professionals' experiences. Health Soc Care Community. 2014;22(4):386-94.

10. Stewart JT, Schultz SK. Palliative Care for Dementia. Psychiatr Clin North Am. 2018;41(1):141-51.
11. Broady TR, Saich F, Hinton T. Caring for a family member or friend with dementia at the end of life: a scoping review and implications for palliative care practice. Palliat Med. 2018;32(3):643-56.

12. Sachs GA, Shega JW, D. C-H: barriers to excellent end-of-life care for patients with dementia. J Gen Intern Med. 2004;19(10):1057-63.

13. Torke AM, Holtz LR, Hui S, Castelluccio P, Connor S, Eaton MA, GA S. Palliative Care for Patients with dementia: a National Survey. J Am Geriatr Soc. 2010;58(11):2114-21.

14. Gozalo P, Plotzke M, Mor V, Miller SC, JM. T: changes in Medicare costs with the growth of hospice care in nursing homes. N Engl J Med. 2015;372(19): 1823-31.

15. May P, Normand C, Cassel JB, Del Fabbro E, Fine RL, Menz R, Morrison CA, Penrod JD, Robinson C, Morrison RS. Economics of palliative Care for Hospitalized Adults with Serious IIIness: a meta-analysis. JAMA Intern Med. 2018:178(6):820-9.

16. Mitchell SL, Teno JM, Miller SC, Mor V. A national study of the location of death for older persons with dementia. J Am Geriatr Soc. 2005;53(2):299305.

17. Sleeman KE, Ho YK, Verne J, Gao W, Higginson IJ. Reversal of English trend towards hospital death in dementia: a population-based study of place of death and associated individual and regional factors, 2001-2010. BMC Neurol. 2014;14:59

18. Mitchell SL, Miller SC, Teno JM, Kiely DK, Davis RB, ML. S: prediction of 6month survival of nursing home residents with advanced dementia using ADEPT vs hospice eligibility guidelines. JAMA. 2010;304(17):1929-35.

19. Mahoney Fl, Barthel DW. Functional evaluation: the Barthel index. Md State Med J. 1965;14:61-5.

20. Folstein MF, Folstein SE, McHugh PR. "mini-mental state". A practical method for grading the cognitive state of patients for the clinician. J Psychiatr Res. 1975;12(3):189-98.

21. Mitchell SL, Kiely DK, Hamel MB, Park PS, Morris JN, BE. F: estimating prognosis for nursing home residents with advanced dementia. JAMA. 2004;291 (22):2734-40.

22. Rothenberg LR, Doberman D, Simon LE, Gryczynski J, Cordts G. Patients surviving six months in hospice care: who are they? J Palliat Med. 2014; 17(8):899-905.

23. Tsai CF, Lee YT, Lee WJ, Hwang JP, Wang SJ, JL. F: depression of family caregivers is associated with disagreements on life-sustaining preferences for treating patients with dementia. PLoS One. 2015;10(7):e0133711.

24. Carlson MD, Lim B, Meier DE. Strategies and innovative models for delivering palliative care in nursing homes. J Am Med Dir Assoc. 2011;12(2): 91-8.

25. Welch LC, Miller SC, Martin EW, Nanda A. Referral and timing of referral to hospice care in nursing homes: the significant role of staff members. Gerontologist. 2008;48(4):477-84.

26. Miller SC, Lima JC, SL. M: influence of hospice on nursing home residents with advanced dementia who received Medicare-skilled nursing facility care near the end of life. J Am Geriatr Soc. 2012;60(11):2035-41.

27. Ahronheim JC, Morrison RS, Morris J, Baskin S. DE. M: palliative care in advanced dementia: a randomized controlled trial and descriptive analysis. J Palliat Med. 2000;3(3):265-73.

28. Huang HK, Hsieh JG, Hsieh CJ, YW. W: do cancer patients with dementia receive less aggressive treatment in end-of-life care? A nationwide population-based cohort study. Oncotarget. 2017;8(38):63596-604.

29. Chen YH, Ho CH, Huang CC, Hsu YW, Chen YC, Chen PJ, Chen GT, JJ W. Comparison of healthcare utilization and life-sustaining interventions between elderly patients with dementia and those with cancer near the end of life: a nationwide, population-based study in Taiwan. Geriatr Gerontol Int. 2017;17(12):2545-51.

30. Lee HT, Cheng SC, Dai YT, Chang M, Hu WY. Cultural perspectives of older nursing home residents regarding signing their own DNR directives in eastern Taiwan: a qualitative pilot study. BMC Palliat Care. 2016;15:45.

31. Kwok T, Twinn S. E. Y: the attitudes of Chinese family caregivers of older people with dementia towards life sustaining treatments. J Adv Nurs. 2007; 58(3):256-62.

32. Mitchell SL, Kiely DK, MB. H: dying with advanced dementia in the nursing home. Arch Intern Med. 2004;164(3):321-6.

33. Clarfield AM, Monette J, Bergman H, Monette M, Ben-Israel Y, Caine Y, Charles J, Gordon M. B. G: enteral feeding in end-stage dementia: a comparison of religious, ethnic, and national differences in Canada and Israel. J Gerontol A Biol Sci Med Sci. 2006;61(6):621-7. 
34. Di Giulio P, Toscani F, Villani D, Brunelli C, Gentile S. P S: dying with advanced dementia in long-term care geriatric institutions: a retrospective study. J Palliat Med. 2008;11(7):1023-8.

35. Hendriks SA, Smalbrugge M, Deliens L, Koopmans RTCM, OnwuteakaPhilipsen BD, Hertogh CMPM. Steen. Vd: end-of-life treatment decisions in nursing home residents dying with dementia in the Netherlands. Int J Geriatr Psychiatry. 2017;32(12):e43-9.

36. Oud L. Predictors of transition to hospice care among hospitalized older adults with a diagnosis of dementia in Texas: a population-based study. J Clin Med Res. 2017;9(1):23-9.

\section{Publisher's Note}

Springer Nature remains neutral with regard to jurisdictional claims in published maps and institutional affiliations.

Ready to submit your research? Choose BMC and benefit from:

- fast, convenient online submission

- thorough peer review by experienced researchers in your field

- rapid publication on acceptance

- support for research data, including large and complex data types

- gold Open Access which fosters wider collaboration and increased citations

- maximum visibility for your research: over $100 \mathrm{M}$ website views per year

At BMC, research is always in progress.

Learn more biomedcentral.com/submissions 